\title{
La transformación estética del espacio educativo y su influencia en el proceso de enseñanza-aprendizaje
}

\author{
The educational facility's aesthetical transformation \\ and its influence on the teaching-learning process
}

Javier Andreo León

Universidad de Jaén

javierandreoleon@gmail.com
Recibido 12/10/2018

Aceptado 11/06/2019

Revisado 14/11/2018

Publicado 14/06/2019

\section{Resumen:}

El objeto de este artículo es el de revisar la relación existente entre el espacio educativo y la influencia que este ejerce sobre el proceso de enseñanzaaprendizaje y sobre el propio desarrollo interpersonal e intrapersonal de los agentes implicados en dicho proceso.

Se valora, de este modo, la educación $y$, concretamente, el acto de educar como modelador y determinante para con la configuración de la persona en su nivel individual y social. Así, el espacio que alberga la actividad educativa se contempla como elemento didáctico que acompaña y pertenece a la actividad como tal.
No se entiende la una sin el otro: el propósito que persigue la educación es el fin del espacio educativo y viceversa. En consecuencia, transformar la educación formal y sus objetivos pasa -que no concluye- necesariamente por la transformación estética del espacio educativo.

\footnotetext{
Abstract:

The aim of this article is to revise the current relationship between educational facility and its influence on the teachinglearning process and over the interpersonal and intrapersonal development itself of the actors involved in such process.
} 
La transformación estética del espacio educativo y su influencia en el proceso de enseñanzaaprendizaje

https://dx.doi.org/10.17561/rtc.n16.5

It values, in this way, education and, concretely, the act of educating as a modeller and decisive in relation with shaping the person in his/her individual and social level as well. Therefore, it contemplates the space which houses the educational activity as an instructional material which accompanies and belongs to the activity.
It isn't understood one without the other: the purpose which pursues the education is the goal of educational facility and vice versa. Accordingly, transforming formal education and its objectives goes -not concludingnecessarily through educational facility's aesthetical transformation.

Palabras Clave desarrollo, transformación, educación, espacio educativo.

Key words development, transformation, education, educational facility.

Sugerencias para citar este artículo

Andreo León, Javier (2019). La transformación estética del espacio educativo y su influencia en el proceso de enseñanza-aprendizaje. Tercio Creciente, 16, págs. 117-143.

https://dx.doi.org/10.17561/rtc.n16.5

ANDREO LEÓN, JAVIER. La transformación estética del espacio educativo y su influencia en el proceso de enseñanza-aprendizaje. Tercio Creciente, julio 2019. $n^{\circ} 16$, pp. 117-143.

https://dx.doi.org/10.17561/rtc.n16.5 


\section{Introducción}

«La realidad está definida con palabras. Por lo tanto, el que controla las palabras controla la realidad» -dice Antonio Gramsci (1973) a propósito del poder de la educación y de la cultura de la sociedad. En este sentido, y sin entrar a valorar hegemonía y dominación, Gramsci concibe la educación como el motor de la revolución en tanto en cuanto el Estado se convierte en educador con el fin de aglutinar mayorías a través del sometimiento ideológico de la masa popular.

La escuela se convierte, entonces, en ese campo de confrontación de contrahegemonía y hegemonía política, así como en escenario de constitución y sobre todo- de perpetuación de la jerarquización y estratificación social. Esto es, la escuela se erige como templo para la reproducción automatizada y estandarizada del "conocimiento" de una generación a la siguiente.

Esta canción suena bastante mainstream y mucho española, no por nada se han aprobado siete leyes educativas diferentes desde los años de la transición. Se legitima con esto esa idea de reconquista continua de los órganos estatales en general y de la educación en particular para utilizarlos al servicio e intereses del Estado en contra de los intereses de la ciudadanía.

Por ello, y más allá de teorías oscurantistas, nos topamos con un sistema educativo asentado en el inmovilismo con métodos que persiguen la transmisión de los saberes enciclopédicos en detrimento del autodesarrollo del alumnado.

$Y$ pese a que en los últimos años, en un intento de democratización de los servicios y espacios públicos, se ha descentralizado el poder estatal para delegarlo, en cuestión de autonomía, en los centros escolares, esto no ha resultado en la consecución de una educación enfocada en el librepensamiento y en el cuestionamiento de nuestras tradiciones, sino todo lo contrario, ha supuesto el surgimiento de nuevas líneas y estratos de poder intermedios: desde los poderes fácticos al AMPA pasando por el Claustro de profesorado.

En consecuencia, alejados de dogmas, supersticiones y demás ortodoxias, nos encauzamos en el devenir de esa escuela-nueva-libre. Libre de imposiciones y seducciones y disruptiva con el sistema fordista alienante dado. En definitiva, libre para ser genuinamente uno mismo y, sobre todo, activa en la construcción y generación del autoaprendizaje y, por consiguiente, en la autorrealización.

Para tal fin, resulta difícil concebir la escuela-nueva-libre (como contenido) dentro de la escuela-vieja-actualrepresora (como continente), edificada como aparato ideológico del Estado para la irreflexión del concepto de autoridad.

Conocido es su principio: en la periferia, una construcción en forma de anillo; en el centro, una torre, ésta, 
La transformación estética del espacio educativo y su influencia en el proceso de enseñanzaaprendizaje

https://dx.doi.org/10.17561/rtc.n16.5

con anchas ventanas que se abren en

la cara interior del anillo. La

construcción periférica está dividida

en celdas, cada una de las cuales

atraviesa toda la anchura de la

construcción. Tiene dos ventanas, una

que da al interior, correspondiente a

las ventanas de la torre, y la otra, que

da al exterior, permite que la luz

atraviese la celda de una parte a otra.

Basta entonces situar un vigilante en

la torre central y encerrar en cada

celda a un loco, un enfermo, un

condenado, un obrero o un escolar.

Por el efecto de la contraluz se

pueden percibir desde la torre,

recortándose perfectamente sobre la

luz, las pequeñas siluetas cautivas en

las celdas de la periferia (Foucault, 2012).

Foucault, al describir el Panóptico de Bentham, revela el origen teórico de una tipología espacial dedicada al ejercicio del control. La organización arquitectónica del espacio asegura y sostiene una relación de poder independientemente de aquel que lo ejerce. Esto es, el recluso, a causa de la incesante sensación inducida de visibilidad termina por ser su propio vigilante. «El detenido no debe saber jamás si en aquel momento se le mira; pero debe estar seguro de que siempre puede ser mirado» (Foucault, 2012).

Bajo esta misma idea de control global se levantan las escuelas orwellianas de nuestros días, en las que, «por una parte, el alumno está siempre expuesto al efecto de la visión por parte del encargado de vigilarlo [...]; por otra parte, el profesor ocupa el punto focal del espacio, estando siempre expuesto ante sus alumnos-espectadores» (Bertozzi, 2001).

Este carácter de atomización y previsibilidad que propone el espacio de la institución escolar estatal, por tanto, guarda una relación directa para con el no-desarrollo crítico individual del alumno.

Entonces, si, según la primera línea del preámbulo de la actual ley central educativa, se constituye que «el alumnado es el centro y la razón de ser de la educación. El aprendizaje en la escuela debe ir dirigido a formar personas autónomas, críticas, con pensamiento propio» (Ley Orgánica 8, 2013), no podemos sino dirigir nuestras miradas y esfuerzos a que así sea de facto $\mathrm{y}$, de igual forma, generar espacios acordes que inviten y promuevan tal fin.

Por consiguiente, el objeto que persigue el presente escrito es el análisis teórico-práctico del espacio educativo y cómo la transformación estética de este, hacia la abstracción y la polivalencia, puede igualmente transformar el proceso en sí de enseñanza-aprendizaje y resultar en una sociedad más crítica y democrática.

\section{La educación como motor para el cambio social}

«Una educación bancaria hacia una libertaria, emancipadora». Con este postulado, Freire (1975) sitúa tanto el origen como el destino proyectado de la educación. Determina y resuelve las 
eternas cuestiones identitarias: ¿de dónde venimos? ¿a dónde vamos? Así, entiende y eleva la educación como objeto vital. ${ }^{1}$

Con la aparición de la escolarización, el medio académico de la pedagogía se enmarca en los discursos de la regulación social: la escuela forma, pero también reprime. Establece, por tanto, mediante la imposición y el ejercicio del poder jerárquico, aquello que ha de hacerse y saberse y aquello que no (Galicia, 2004).

Las formas de gobierno, en consecuencia, encuentran en la educación ya no solo un sistema garantista de estrella que perpetúa el cierre social entendido como el conjunto de estrategias de distribución y segregación que derivan en la desigualdad social y, así, en el mantenimiento de los estratos de clase, sino que, y del mismo modo, el cierre social adquiere un nuevo orden al ocuparse de la asignación del conocimiento y de la exclusión de este, con lo que el asistir a la escuela ya no es sinónimo de educación para todos.

Se constituye, entonces, la dialéctica saber-poder foucaultiana, aquella que plantea la voluntad de verdad como voluntad de poder. Esto es, advertir el saber como instrumento del poder. Para Foucault, detrás de la fachada de la verdad subyace toda una voluntad de

\footnotetext{
${ }^{1}$ Vital entendido en su doble acepción: 1 . adj. Perteneciente o relativo a la vida; 2 . adj. De suma importancia o trascendencia (Real Academia Española, 2017).
}

poder, una justificación para la dominación, para exigir conformidad y sumisión. $Y$ es que el conocimiento, el saber, supone una doble represión: la que condena al silencio los discursos "excluidos" y la que discierne y ordena los discursos "aceptables" (Ovejero \& Pastor, 2001).

Aparece aquí el discurso como práctica institucional y disciplinar mediante la cual se participa en la formación, funcionamiento y difusión de lo políticamente aceptado e impuesto desde las instancias de poder. Los discursos son aquello que posibilita las disciplinas y las instituciones a partir de las cuales se sostienen y redistribuyen las ideologías (Galicia, 2004).

Por ende, se presenta como obligado, ante este escenario que profundiza en el proceso de cambio social, la reformulación de las preguntas básicas sobre los fines que persigue la educación, sobre quiénes asumen la responsabilidad de formar a las nuevas generaciones y sobre qué legado cultural, qué valores, qué concepción del hombre y de la sociedad se desea transmitir (Tedesco, 1995).

Y es que, más allá del ejercicio del poder y la dominación por sí mismos, subyacen intereses que abogan por el "desarrollo" social, como los promulgados, por ejemplo, por la OCDE (Organización para la Cooperación y el Desarrollo Económicos), a la que el Estado rinde cuentas en el preámbulo de la LOMCE (Ley Orgánica 8, 2013), esto es, subyugar por y para el progreso, por 
La transformación estética del espacio educativo y su influencia en el proceso de enseñanzaaprendizaje

https://dx.doi.org/10.17561/rtc.n16.5

y para el emprendimiento, la competitividad y productividad, esto es, por y para el capital.

Decía el rapero -ahora condenado por la Audiencia Nacional por los delitos de enaltecimiento del terrorismo, injurias a la Corona y calumnias a las Instituciones del Estado por ejercer la libre expresiónPablo Hasél (2011) en el estribillo de una canción para con la educación:

La educación es la base y la controla el capital.

Quieren mentes obtusas que no se sepan informar.

Que crean lo que sale en la cope o el país.

Hacen lo imposible pa que tu percepción no se pueda abrir.

La educación es la base y es antirrevolucionaria.

Echo la vista atrás y sólo aumenta mi rabia.

\section{Cuando veo cómo me ocultaron lo} más importante.

Pero no pudieron evitar que hoy la realidad cante.

Con la Revolución Industrial y las heredadas políticas neoliberales, el desarrollo de las políticas públicas en general y en el área educativa en particular redefine, con el sistema de globalización, la relación Estado y Mercado, así como la política con interés económico privado a favor de la lógica de mercado (Dufour, 2016).
Así pues, «...díganme dónde está el trabajo en un tipo de sociedad y les diré dónde está la educación» (Mészarós, 2008). Por consiguiente, se define un horizonte educativo y pedagógico que atiende a los conceptos de la oferta y la demanda, de modo que la educación -y con ella, la sociedad- termina por avanzar al ritmo que exige la economía global y por supuesto no al revés.

En este marco, todo termina por ser susceptible de ser mercantilizable, todo se vende, todo se compra, y la educación no es una excepción. La lógica alienante del consumo y el lucro no hace sino transformar los espacios educativos en centros comerciales. En los que se acumula sin más sentido que el de acumular, se conoce, pero no se comprende. Esto es, se reproduce el discurso mediático en contra de su desciframiento, en contra del despertar.

El efecto de mercado global determina con él una suerte de escenario único estandarizado que erradica de golpe la identidad cultural singular de los pueblos en pro de una identidad común a todos. Se genera, así, un proceso total de macdonalización y disneylandificación, en el que, bajo una aparente capacidad masiva de elección y diversidad, se esconde un sistema caracterizado por la previsibilidad, la uniformidad y la automatización (López Cuenca, 2015).

Los libros y las obras de arte están a nuestra disposición como nunca antes lo habían estado. Nuestra propia vida está llena de acontecimientos. Pero, al mismo 
tiempo, casi nada nos pasa. Los sucesos de actualidad, convertidos en noticias fragmentarias y aceleradamente caducas, no nos afectan en lo propio... Consumimos libros y obras de arte, pero siempre como espectadores... Sabemos muchas cosas, pero nosotros mismos no cambiamos con lo que sabemos (Larrosa, 2009).

Nos encontramos, por todo, inmersos en una realidad social compleja en la que la soberanía del Estado queda en entredicho al encontrarse supeditada y totalmente traspasada por los poderes fácticos, por las grandes compañías multimillonarias -en muchas ocasiones con mayor PIB que la totalidad del país en cuestión- ${ }^{2}$. El poder cambia de manos, mejor dicho, se disgrega, porque nadie quiere renunciar a su trozo de la tarta. Así, la política y la religión continúan su

\footnotetext{
2 «[...] al listar las naciones de acuerdo con el volumen de su Producto Interno Bruto, el país No. 15 se llama General Motors, y el 16, Exon Company... En 1994, el Producto Interno Bruto de El Salvador era de 8,070 millones de dólares; en el mismo año, la facturación de Mitsubishi era de 175,800 millones de dólares; Mitsui facturaba 171,500 millones de dólares; Sumitomo 162,500 millones de dólares; General Motors 155,000 millones de dólares... Es decir, 20 o 22 veces el Producto Interno Bruto de El Salvador. Al ser estas megaempresas veinte veces más poderosas que muchos Estados, arrollan nuestras fronteras con sus productos y capitales. En realidad, no necesitan arrollar las fronteras porque la teoría imperante ordena que los Estados deben facilitar los flujos de mercancías y capitales y fomentarlos con subvenciones inmensas y que en tamaño superan la cantidad de subvenciones que el Estado Social jamás haya efectuado» (Ibisate, 1998).
}

ejercicio del sometimiento ideológico al tiempo que actúan de muletas del gobernante global, el capitalismo.

Todos estos núcleos de poder encuentran su nexo y aglutinante en lo que nos ocupa, en la educación. El discurso del capital y del progreso se traslada a las escuelas y se traduce en el emprendimiento como tratamiento trasversal a todas las áreas, el preámbulo de la LOMCE (Ley Orgánica 8, 2013) no alberga dudas al respecto:

La lógica de esta reforma se basa en la evolución hacia un sistema capaz de encauzar a los estudiantes hacia las trayectorias más adecuadas a sus capacidades, de forma que puedan hacer realidad sus aspiraciones y se conviertan en rutas que faciliten la empleabilidad y estimulen el espíritu emprendedor a través de la posibilidad, para el alumnado y sus padres, madres o tutores legales, de elegir las mejores opciones de desarrollo personal y profesional.

Y, aunque el espíritu emprendedor no es una cuestión negativa a priori, sí lo es su carácter reduccionista. Todo apunta y concluye en la asunción del sistema de trabajo y capital y en el no cuestionamiento de este. Todo apunta al "puedes lograrlo si te esfuerzas lo suficiente" frente al "si no lo logras es tu culpa" thatcheriano, al "subirse a la bici"3

${ }^{3}$ «Norman Tebbit, uno de los hombres de confianza de Thatcher, tras las grandes manifestaciones de los 80 que protestaban contra el nivel tan alto de paro ocasionado por las políticas 
La transformación estética del espacio educativo y su influencia en el proceso de enseñanzaaprendizaje

https://dx.doi.org/10.17561/rtc.n16.5

como modus vivendi, a reproducir y perseguir el modelo Amancio Ortega.

Se traslada a la escuela y al aula, como decimos, toda una estructura que trasciende a la propia educación, pero que encuentra en esta su motor y su razón de ser.

Asistimos, como corolario, a una escuela siempre paladina del desarrollo social y siempre cómplice del contradesarrollo social. No podemos sino hallar en ella toda una estamentación y entramado que así lo permita a través de una mezcolanza más o menos (poco) cohesionada que, de un lado, se parapeta y atrinchera en la consecución del respeto (que es miedo) hacia la figura de poder totalitarista, de otro lado, se rinde a su posición para esparcir la buena nueva particular $\mathrm{y}$, por último, se resigna y asume su papel de operario como en una cadena de trabajo fordista.

A propósito de este último, que bebe del modelo industrial y que acepta como propio el sometimiento que ejerce la escuela -tanto al alumnado como al profesorado, que no es sino posalumnado y fruto germinado del sistema- Ferrer i Guardia, fundador de la

de desindustrialización, dijo: "cuando mi padre perdió su trabajo a principios de los 30 , no protestó; se subió a su bici y buscó trabajo". Y esa idea de "subirse a la bici" se convirtió en un eslogan nacional, que venía a decir que, si estabas desempleado, no era culpa de la sociedad ni del gobierno, era tu propia responsabilidad. Con lo que desarmaba toda posible colectivización, intentando capturar ese sentido de nueva modernidad de individualismo en el que puedes hacer lo que quieras» (Jones, 2017).
Escuela Moderna -recoge Spring (1987)admitía que, una vez superado el estado de ignorancia por el cual los gobiernos controlaban las masas, la estructura jerárquica del capitalismo exigía que los trabajadores tuvieran ciertos rasgos de carácter específicos. Se les debía educar para que soportaran el aburrimiento y la monotonía de la fábrica y para que aceptaran obedientemente su organización. Los trabajadores debían ser puntuales, obedientes, pasivos, y además estar deseosos de aceptar su empleo y su posición.

Con lo que, este bagaje, que converge en un engranaje conformista, estatista e individualista en cuanto a los órganos internos de la escuela, vende, en favor de los think tanks, la dirección de la educación que haya de servir a la ciudadanía. Por ello, los Otros obtienen en el cuerpo docente ese ejército fiel que se posiciona en primera línea, que ejecuta y no cuestiona.

Para suerte de todos y para romper con el ciclo previsto ad infinitum, existen, de igual forma, buena cantidad de docentes comprometidos con dinamitar una educación deshumanizada que se concibe a sí misma como una suerte de testigo que se pasa de generación en generación.

Esta es la idea que plasmó la artista estadounidense Anna Hyatt Huntington en la obra escultórica monumental Los portadores de la antorcha, que donó a la ciudad de Madrid en 1955. La escultura muestra a un joven a lomos de un fornido caballo recogiendo una antorcha de las 
manos de un yacente anciano como último y heroico acto tras el largo caminar, que representa, como adelantábamos, la transmisión del conocimiento entre generaciones.

Viene a ilustrar la concepción predominante de la educación como un saber estanco sin acumulación en contra de la contribución -no ya en términos generacionales sino individuales- de cada uno a un saber común, que debería ser acumulativo pero que no lo es. En este caso -y aludiendo al estado de mutilación actual en el que se encuentra la estatua en cuestión- no solo no se está acumulando el saber, sino que ni siquiera se está transmitiendo, lo que resulta en un presunto paso del testigo en falso (Castro, 2018).

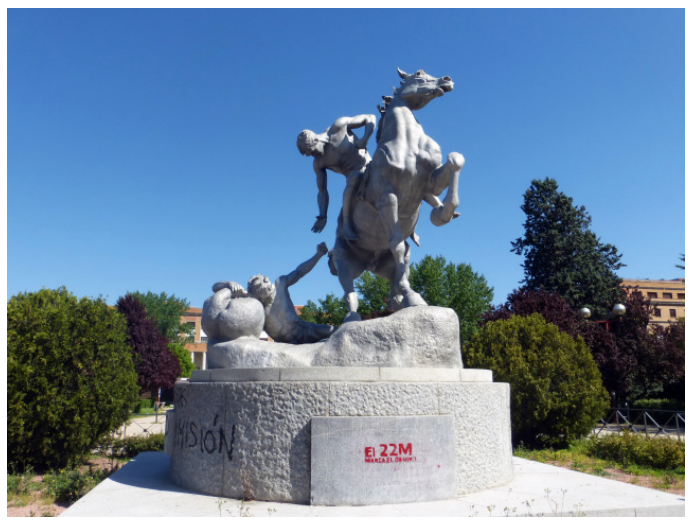

Figura 1. Los portadores de la antorcha, Anna Hyatt Huntington. Ciudad Universitaria de la Universidad Complutense de Madrid. Fuente de la imagen: (Brown, 2014).

Se obvia, por tanto, que todo proceso de transmisión y toda narración implica de algún modo la apropiación de la lengua, un movimiento que hace respirar algo del pasado y lo reinventa, con lo que se genera una suerte de inmovilización del saber y del hacer. El lenguaje y la historia quedan, así, cancelados y el conocimiento y la propia subjetividad, despojados de las marcas de la experiencia. Del mismo modo, al nombrar la educación en términos de transmisiones fallidas o logradas, como en función de resultados, arrinconándola en la esfera de los productos fabricados, va quedando fuera la densidad de una travesía que guarda acontecimientos, singularidades impredecibles, relaciones múltiples y fluidas (Rattero, 2009).

Con la reducción objetual de la educación, llegamos a una visión y aplicación de esta en la que su función casi se sustenta en su disfunción, en una transmisión de esta que termina por ser una representación teatral de la acción misma de transmitir. Quedan, por tanto, el decorado, los actores, el público y una obra que deviene en los elementos, en la pantomima.

Salvando las distancias conceptuales y contextuales, resultaría una pieza paralela a 4'33" de John Cage, esto es, la estructura formal y la jerarquización de roles está dispuesta, pero, por encima de todo, el tacet, ${ }^{4}$ la inacción activa, o en el caso educativo, la acción pasiva.

\footnotetext{
${ }^{4}$ Tacet es un término utilizado en notación musical para indicar que el intérprete de un instrumento o voz no debe sonar. En la partitura de 4'33', más allá del tiempo estipulado de duración de la pieza, cuatro minutos y treinta y tres segundos, figuraba este único elemento, tacet.
} 
La transformación estética del espacio educativo y su influencia en el proceso de enseñanzaaprendizaje

https://dx.doi.org/10.17561/rtc.n16.5

La narración, cuyo sujeto es el educador, conduce a los educandos a la memorización mecánica del contenido narrado. Más aún, la narración los transforma en "vasijas", en recipientes que deben ser "llenados" por el educador. Cuanto más vaya llenando los recipientes con sus "depósitos" tanto mejor educador será. Cuanto más se dejen "llenar" dócilmente, tanto mejor educandos serán. De este modo, la educación se transforma en un acto de depositar en el cual los educandos son los depositados y el educador quien deposita... (Freire, 1975, pág. 51)

Así, Freire señala que la ignorancia alienante es un producto directo de la transmisión de la información en contra de la comunicación.

Tal es la concepción "bancaria" de la educación, en que el único margen de acción que se ofrece a los educandos es el de recibir los depósitos, guardarlos y archivarlos. En la visión "bancaria" de la educación, el "saber", el conocimiento, es una donación de aquéllos que se juzgan sabios a los que juzgan ignorantes. Donación que se basa en una de las manifestaciones instrumentales de la ideología de la opresión: la absolutización de la ignorancia, que constituye lo que llamamos alienación de la ignorancia, según la cual ésta se encuentra siempre en el otro. (Freire, 1975, pág. 52)

Esto es, la información es un acto unidireccional, orientado a la transmisión.
Si el educador es quien sabe, y si los educandos son los ignorantes, le cabe, entonces, al primero, dar, entregar, llevar, transmitir su saber a los segundos. Saber que deja de ser un saber de "experiencia realizada" para ser el saber de experiencia narrada o transmitida. No es de extrañar, pues, que en esta visión "bancaria" de la educación, los hombres sean vistos como seres de la adaptación, del ajuste. Cuanto más se ejerciten los educandos en el archivo de los depósitos que les son hechos, tanto menos desarrollarán en sí la conciencia crítica de lo cual resultaría su inserción en el mundo, como transformadores de él, como sujetos del mismo. Cuanto más se les imponga pasividad, tanto más ingenuamente tenderán a adaptarse al mundo en lugar de transformar, tanto más tienden a adaptarse a la realidad parcializada en los depósitos recibidos. En la medida en que esta visión "bancaria" anula el poder creador de los educandos o lo minimiza, estimulando así su ingenuidad y no su criticidad, satisface los intereses de los opresores (Freire, 1975, pág. 53).

Sin embargo, la comunicación es un proceso de doble vía, posible cuando entre los dos polos de la estructura relacional rige una ley de bivalencia: todo transmisor puede ser receptor, todo receptor puede ser transmisor (Pasquali, 1967).

Desaparece, por tanto, la relación de jerarquía vertical a favor de una relación 
horizontal. De la comunicación, del diálogo, resulta una matriz crítica que genera criticidad. "Cuando los dos polos del diálogo se ligan así, con amor, con esperanza, con fe el uno en el otro, se hacen críticos en la búsqueda común de algo. Sólo ahí hay comunicación. Sólo el diálogo comunica» (Freire, 1975).

En consecuencia, el diálogo, dentro de este marco de cambio político y educativo, se posiciona como una estrategia para la reconstrucción de un lenguaje y unas prácticas de resistencia. De tal modo que, a partir de la pedagogía crítica dialógica, se proyecte una cultura politizada que trascienda de lo formal y lo simbólico para devenir en el lugar de la producción y lucha contra la hegemonía, contra el poder. Esto es, el diálogo, el nosotros, entendido como acción democrática para la consecución de una cultura y política democrática y, con ello, una sociedad democrática, entendida como una sociedad de consenso de y entre iguales.

Estas premisas nos hacen entender el aprendizaje como participación activa y reflexiva y como construcción y transformación común social, cultural y política para lograr, así, la emancipación y la liberación.

«Contrariamente a la educación para la domesticación, la educación para la liberación, que es utópica, profética y optimista, es un acto de conocimiento y un medio de acción que permite transformar la realidad que debe ser conocida» (Freire, 1971).
De tal manera, y como se ha determinado que la pedagogía o el aprendizaje basado en el diálogo puede suponer "la chispa que incendia la pradera", para la comprensión y consecución de ese aprendizaje dialógico, Flecha (1999) establece unos principios sobre los que se basa:

1. El diálogo igualitario. Las diferentes aportaciones son consideradas en función de la validez de los argumentos y no desde criterios como la imposición de un saber culturalmente hegemónico.

2. La inteligencia cultural. Es un concepto más amplio de inteligencia que los habitualmente utilizados, no se reduce a la dimensión cognoscitiva basada en la acción teleológica, sino que contempla la pluralidad de dimensiones de la interacción humana.

\section{La transformación. El} aprendizaje dialógico transforma las relaciones entre la gente y su entorno. Es un aprendizaje que se basa en la premisa de Freire de que las personas somos seres de transformación y no de adaptación.

4. La dimensión instrumental. No se obvia ni se contrapone a la dialógica. El aprendizaje dialógico abarca todos los aspectos que se acuerde aprender.

5. La creación de sentido. Para superar la colonización del mercado y la burocrática y, de este modo, evitar 
La transformación estética del espacio educativo y su influencia en el proceso de enseñanzaaprendizaje

https://dx.doi.org/10.17561/rtc.n16.5

que se imponga una lógica utilitarista hay que potenciar un aprendizaje que posibilite una interacción entre las personas dirigida por ellas mismas.

6. La solidaridad. Como expresión de la democratización de los diferentes contextos sociales y la lucha contra la exclusión que se deriva de la dualización social, es la única base en que se puede fundamentar un aprendizaje igualitario y dialógico.

\section{La igualdad de diferencias. Es} contraria a la adaptación a la diversidad que relega la igualdad y que ha regido algunas reformas educativas.

Entonces, sin caer en la ingenuidad, siendo conocedor del fuerte viento que sopla en contra de esa "chispa", se presenta imperioso el surgimiento de otras chispas aliadas cómplices a la causa de incendiar la pradera, o, al menos, de retar y retener la virulencia del vendaval.

Esto es, de nada sirve el diálogo si la estructura y la organización escolar y cultural no se construye en base al diálogo sino en base a las relaciones jerárquicas de poder. En efecto, el diálogo es la chispa, pero la pradera, lejos de intuirse como la otredad, se muestra en forma de Escuela.

Así pues, la escuela ha de entenderse como un contexto de acción colaborativa y de interacción, como un lugar no coercitivo y alejado de la trinchera, en el que actuar y aprender libremente está permitido, en el que el saber está supeditado al sentir. Ha de entenderse como un diálogo no de intramuros sino para con el entorno (familias, barrio...), sin advertir distinciones entre afuera y adentro para concebir una realidad común.

De esta forma, así como el contexto o la comunidad o el andamiaje vygotskiano se establece como una segunda chispa amiga de la educación libertaria, el contexto físico educativo ha de suponerse como esencial en tanto en cuanto es el escenario tangible donde se libra la acción. No tendría sentido luchar para reestablecer las relaciones entre los seres vivos y la corriente de un río y obviar, por otro lado, la opresión que ejerce sobre el río su propio lecho. ${ }^{5}$

Debemos, por tanto, construir una escuela física que se base sobre las premisas de la Escuela libre. Que proponga y no imponga, que invite a la experimentación y al desarrollo vital natural.

\section{El espacio educativo como elemento didáctico}

"La experiencia de los niños debería ser el alimento de la escuela: su vida, sus sorpresas y sus descubrimientos»-dice Francesco Tonucci "Frato" (2013)- «Mi maestro -sigue- siempre nos hacía vaciar los bolsillos en clase, porque estaban

\footnotetext{
${ }^{5}$ «Al río que todo lo arranca lo llaman violento, pero nadie llama violento al lecho que lo oprime» On Violence. Bertolt Brecht.
} 
llenos de testigos del mundo exterior: bichos, cuerdas, cromos, boliches...» y es que ese maestro seguramente estaba intentando evitar distracciones, pero ¿distracciones de qué?, es decir, ¿qué es lo esencial, sino los indicios de la vida?

En muchas ocasiones encontramos relaciones entre los elementos que componen el aula y la distracción que provocan en el aprendizaje del alumnado. Nada ha de interferir en la recepción de esa información que transmite el docente. Las palabras que pronunció Alain al respecto de las paredes del aula son bastante esclarecedoras: «No apruebo que se cuelguen de ellas cosas para mirar, aun bellas, pues es necesario que la atención se vuelva al trabajo» (Trilla \& Puig, 2003).

No es que Alain fuese un decorador minimalista adelantado a su tiempo o un docente sensible al TDAH, es que era muy consciente del propósito que cumple la distribución y organización de los espacios educativos. El aula debía ser ese lugar destinado a la instrucción y al correctivo, y todos los componentes de esta habían de servir a tales fines. Nada ni nadie podía enturbiar lo que allí se gestaba: el poder disciplinario foucaultiano.

El discurso del poder -como veíamosencuentra en el diseño espacial un aliado que perpetúa el ejercicio del poder por encima incluso de aquel que lo aplica, es decir, el escenario, imperecedero, marca las pautas de relación que alberga, así entre las personas como para con el propio espacio. Atiende, por tanto, a los principios educativos: la disciplina, la imitación, la asimilación de los conceptos de autoridad y jerarquía por encima del discurso en sí, esto es, el cómo por encima del qué.

Así, en la institución educativa, el aula se convierte en un microgobierno en el que gobernante y gobernados quedan bien definidos. El docente, desde su palestra pedestal, exige atención y pleitesía, y el alumnado, que es un conjunto de alumnos individuales despojados de cualquier autonomía y posible asociación entre iguales, se la rinde. Se establece, por tanto, el doblegamiento no solo ideológico sino físico. La escuela es un entrenamiento, un adiestramiento para la inserción en el sistema hegemónico laboral.

Entonces, si en la fábrica o en la oficina se persigue la estandarización y la normalización, que deshumaniza al trabajador para objetualizarlo y convertirlo en una pieza más de la cadena, la escuela hará lo propio para desproveer la identidad del alumno, su idiosincrasia, la individual y la colectiva.

En consecuencia, para no rendir tributo a esos espacios dedicados a la sumisión, no podemos construir instituciones y espacios que derivan de su inspiración. Imitarlos en algún punto sería faltar al propósito de cambio, sería una caricatura de la contrahegemonía en sí. 
La transformación estética del espacio educativo y su influencia en el proceso de enseñanzaaprendizaje

https://dx.doi.org/10.17561/rtc.n16.5

Para la liberación de la imitación, proclamamos el «soy la hora roja, la hora desatada roja ${ }^{6}$ de Césaire, el ideólogo de la negritud. Debemos mudar la piel y desarrollar un pensamiento nuevo para crear hombres nuevos, como exponía Frantz Fanon, que habla del hombre descolonizado, que forzosamente aporta una nueva forma de humanidad.

Esa concepción del hombre poscolonial como el hombre nuevo, así como la propia negritud se extrapolan de su contexto e incluso de la identidad y la conciencia negra para devenir en la raza de los que son oprimidos. Por lo tanto, para hallar esa nueva humanidad propia, no basta con blanquearse la cara para adoptar los privilegios de los opresores, se trata de conquistar la libertad a través de la emancipación, de la transmutación.

Por lo que no basta con maquillar el aula y el espacio educativo actual, la solución ya no pasa por colgar de las paredes cosas bellas para mirar, ni en redecorar la institución hacia un tendente diseño nórdico. El lavado de cara estético puede suponerse como positivo en un principio, pero no puede distraernos del verdadero problema, es decir, que el poder vista en camiseta y zapatillas en lugar de en chaqueta y corbata puede

\footnotetext{
${ }^{6}$ Esta frase la dice un esclavo rebelde en la obra de teatro Et les chiens se taisaient [Y los perros callaban], escrita por Aimé Césaire en 1958. «En ese contexto, "la hora desatada" era el momento de enfrentarse a algo, de elegir, de tomar una decisión, y una decisión importante, porque el esclavo se jugaba la vida, pero para él la libertad era más importante que la vida» (Pallier, 2018).
}

significar un intento por aproximarse a la realidad común popular igual que la remodelación de la escuela puede indicar una preocupación por el bienestar del alumnado, pero el poder en zapatillas seguirá sometiendo y el aula panóptica de estilo IKEA será su aliada.

Esta renovación estética está en auge bajo las alas de grandilocuentes palabras como innovación docente, que se acaba convirtiendo en un terreno que promociona los fuegos artificiales y el espectáculo, de nuevo el cómo por encima del qué, con el agravante de que nadie cuestionaría un buen show.

Encontramos, por ejemplo, proyectos de "humanización del espacio" que en su principio está el mejorar las experiencias y relaciones humanas alrededor de un espacio. Aquí, la "humanización" tiene lugar a través del color, es decir, la estructura espacial permanece inmutable y lo que cambia es la percepción psicosensorial en relación con el lugar, es decir, la transformación que ejerce el color no se da tanto en el plano físico sino en los estímulos que provoca. Con lo que esa pretendida "humanización" se traduce en una suerte de "armonización", es decir, en convertir la estancia en ese espacio en una experiencia más grata.

Los órganos institucionales ceden ante el renovarse o morir y adoptan un aire menos siglo XVIII que contente a la masa no crítica popular y que actúe, a su vez, de reclamo dentro de la oferta. Así, ahora, la distracción que pueda conllevar la redecoración de -en nuestro caso- el aula se contempla como un mal menor. 
Casi resulta un complemento al efecto anestesiante del atiborre de información vía TIC.

En el área hospitalaria, esta humanización del espacio se concibe aparte de como el reclamo diferenciador mencionado- como una distracción intencionada para el usuario. Esta ambientación amigable termina por convertirse en un producto más, pero al mismo tiempo se establece como una herramienta loable que no solo posibilita, sino que refuerza las relaciones humanas.

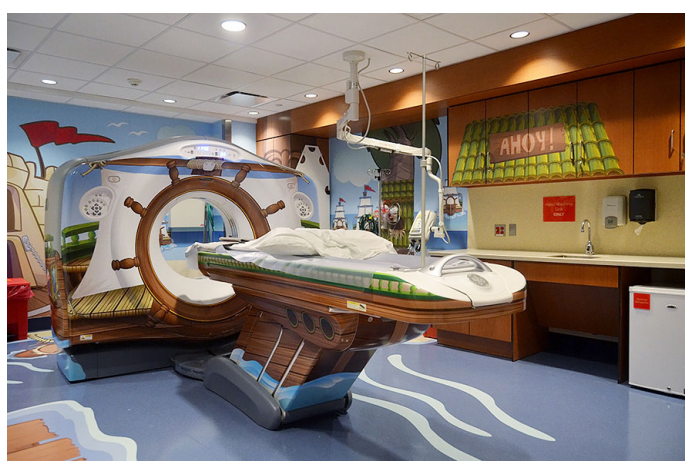

Figura 2. Sala pediátrica de pruebas de TC en el NewYork-Presbyterian Morgan Stanley Children's Hospital.

Y es que la ambientación, la estética de un espacio es la primera sensación y relación que adquirimos para con este. El ambiente armónico se interpreta como información para el sistema nervioso, que determina si es peligroso o no para la supervivencia, si es placentero o doloroso. La psicología ambiental dispone aquellos colores y ambientes que pueden resultar placenteros, por lo que el cuerpo identificará esa experiencia como positiva y querrá repetirla en el tiempo (Di Paolo).

Entonces, esa distracción "de lo importante" que causaba el color como elemento decorativo, en realidad no es sino una atracción, una captación de la atención, pues «la capacidad de captar y centrar la atención es el paso previo al aprendizaje y la memorización» (Di Paolo).

Esta estrategia de generar espacios asociados al bienestar para lograr y predisponer una mayor receptividad que actúa como antesala de la concentración apunta en una sola dirección: mejorar el rendimiento.

Así lo recoge un estudio de la Universidad de Salford, Manchester, cuyo objetivo era el de probar la eficiencia de un sistema espacial educativo que pueda estandarizarse y reducir costes en la construcción de estos nuevos espacios. El hallazgo arrojaba que casi tres cuartas partes de las variables del rendimiento del alumnado podía atribuirse al diseño y a los factores ambientales. Se concluyó que, en "igualdad de circunstancias", el rendimiento académico en un ambiente "rico" podía esperarse un $25 \%$ mayor que en un ambiente educativo "pobre". Los factores tenidos en cuenta fueron: la iluminación, los niveles de ruido, la orientación del aula, la temperatura y la calidad del aire, así como la flexibilidad del espacio, la disponibilidad de almacenaje y la estructura del color (School of the Built Environment, 2012). 
La transformación estética del espacio educativo y su influencia en el proceso de enseñanzaaprendizaje

https://dx.doi.org/10.17561/rtc.n16.5

Se culmina, entonces, con la seudonormalización del estilo Google, esto es, construir espacios que proyecten la idea y sensación de bienestar, de distensión, de felicidad, que fomenten el flujo y la interacción de personas para compartir conocimientos y experiencias y derivar en un incremento de la productividad de los trabajadores. La ecuación es sencilla: empleados felices $=$ buenos resultados. Así, la sensación de bienestar deja paso a la economía del bienestar, esto es, convertir en funcional y eficiente el bienestar social.

Google entiende que cuidar el ambiente circundante al trabajador -tanto el laboral como el personal (con primas, vacaciones...)- resulta directamente en un mayor ánimo de este por satisfacer los objetivos de la compañía. El trabajador aquí no se considera como un operario o como un eslabón más de la cadena, totalmente reemplazable, sino que se espera de él su completa capacidad y dedicación para desarrollar proyectos de forma autónoma, diligente y creativa. El trabajador, desde su campo, participa de la toma de decisiones, lo que implica que este sentirá la empresa como suya en cierta medida, y así, un mayor compromiso para con ella.

Esta fórmula supone un gran salto respecto del escalón anterior en las pretensiones educativas. Si antes se buscaba la cualificación necesaria para desempeñar labores concretas del mundo industrial, la compleja realidad global actual pone sobre la mesa la nueva meta a alcanzar: la excelencia, esa palabra que ha terminado por perder su significado y su valor exclusivo al convertirse en mainstream. Si todo el mundo es excelente, ya nadie lo será.

A parte de la excelencia, el modelo Google, a través de la delegación de responsabilidades, deja entrever un proceso esencial para la construcción de la anhelada sociedad crítica y democrática: el empoderamiento. Sin embargo, este sería un empoderamiento prestado y condicionado, que de algún modo trata de hacer olvidar al trabajador su condición subordinada de proletario, generando así una cubierta de autoconfianza que destierra el auto- para trocarse en confianza.

De tal manera, emancipación y gobierno se presentan como contrarios. No existirán en el mismo plano la liberación y la tutela, la independencia y la dependencia. Por lo que no tendrá sentido pretender la autodeterminación bajo una estructura opresora que la juzgue.

Dicho de un modo mucho más pragmático: ¿cómo puede uno sentirse en la osadía de la autonomía cuando la escuela ha designado para ti un espacio específico que encasilla tu movilidad? Solo existen dos vías para relacionarse con la escuela y con el aula: o bien o mal. Has de sentarte correctamente en tu silla designada (espalda pegada al respaldo, las cuatro patas en el suelo...) tras tu pupitre designado y orientado hacia el profesor y la pizarra.

Si se ha probado que el Aprendizaje Basado en Proyectos -o Problemas- y el 
cooperativismo fomenta esa autonomía del alumnado, ¿qué sentido tiene que se organice el aula mediante mesas individuales? Si se comprende que la educación debe centrar el foco en el autoaprendizaje del alumno, ¿por qué dirigir la posición y atención de este hacia el profesor? Al igual que difícilmente se entablará un debate común si los agentes implicados no pueden verse entre sí.

Del mismo modo, no servirá de nada renovar el espacio educativo sin reformar las practicas docentes. En este sentido, y como pequeña anécdota del proceso de las prácticas de enseñanza en el centro escolar que se me concedió, un profesor no compartía la disposición grupal de las mesas del aula puesto que aquellos alumnos que estaban sentados de espalda a la pizarra tenían que girar el cuello para lograr ver y atender la lección que se explicaba. Así que -y esto lo añado yo- por prevenir la tortícolis, se descartó el "cooperativismo".

La organización -y, sobre todo, la transformación- del aula, por tanto, no puede suponer una cuestión de moda y tendencia estética, ni siquiera funcional o práctica.

La forma en la que se distribuyan los pupitres condiciona completamente el tipo de relación que se establece entre maestros y

alumnos, entre los mismos

estudiantes y entre ellos y el aprendizaje. Dependerá, pues, de la metodología didáctica que se use, pero también de la jerarquía relacional y social que se persiga la forma en que deberá estar distribuido el mobiliario en el aula, orientados los pupitres o ubicado el profesor. (Montero, 2017).

Esto es, no puede suponer un fin, ni otro medio más que disfrace viejas prácticas, como lo es las TIC actualmente, que se han instaurado como un libro de texto "vistoso".

La transformación del espacio educativo ha de concebirse como una herramienta para el aprendizaje libertario y para el empoderamiento del alumnado. Ha de suponer un paisaje que perpetúe la contrahegemonía del mismo modo que el Panóptico de Bentham aseguraba el ejercicio del poder y el sometimiento tan solo con la disposición espacial.

Luego, para evitar espacios coercitivos o meros cambios decorativos que trabajen en la línea de la captación, la consecución de un paisaje de aprendizaje tendrá lugar en tanto en cuanto este genere retos y desafíos que impliquen alcanzar el autoaprendizaje mediante el asombro y el descubrimiento propio.

Por ende, debemos virar el aspecto neutralizante y aséptico de las aulas actuales hacia espacios que beban de los procesos naturales, pues no hay realidad con más vida, sorpresas y descubrimientos que la propia naturaleza.

Si no ha caminado mucho por áridas llanuras, si no han quemado 
La transformación estética del espacio educativo y su influencia en el proceso de enseñanzaaprendizaje

https://dx.doi.org/10.17561/rtc.n16.5

sus pies ardientes arenales, si nunca le colocó la ardiente reverberación de los roquedales encendidos por el sol, ¿cómo queréis que el aire fresco de una hermosa mañana sea capaz de deleitarle? ¿cómo pueden embriagar sus sentidos el aroma de las flores, el verdor de las plantas perladas de rocío y el suave y mullido andar por el césped? ¿qué clase de emoción le causará el trinar de las aves si todavía desconoce los acentos del amor y del placer? ¿cómo puede exaltarle el nacimiento de un día tan hermoso, si su imaginación aún no le sabe pintar los goces con que llenarle? Y, por último, ¿cómo le ha de entender la belleza del espectáculo de la naturaleza si ignora cuál es la mano que con tanto cuidado la engalanó?

(Rousseau, 2011).

La naturaleza, como antítesis del nolugar, se convierte entonces en ese espacio no formal en el que articular un diálogo que se centra en el proceso del propio diálogo. La naturaleza es, por tanto, un marco donde prescindir del artificio y del excedente para establecer un encuentro con el origen, con nosotros mismos. Esto no es practicar la renuncia, es, en esencia, vivir. Es entender que la naturaleza no es un lugar al que ir, sino que es cada uno de nosotros.

Así, al asumir esta dimensión de la natura, nos permite atender a la individualidad dentro de la colectividad, con lo que, a través de la observación y la exploración, somos capaces de comprender y asimilar los elementos, procesos y fenómenos que conforman la realidad de un modo significativo al asumirlos como propios.

Esta curiosidad y asombro que nos suscitan los problemas y soluciones que ofrece el contexto natural se traduce en aprender a aprender de la vida y para la vida, lo que nos permite mejorar el desarrollo cognitivo y ampliar la capacidad de razonamiento.

Con todo, esta apología de la naturaleza como ambiente enriquecedor y didáctico no pretende establecer que la solución definitiva pase por derribar las escuelas y trasladarnos a los montes, bosques o llanuras -que por un lado, y más allá del despertar de una conciencia ecologista y de una actitud armoniosa con nosotros mismos y con la comunidad (que podría significar la reducción de los abusos y conflictos escolares), el contacto con la naturaleza (y no la imagen de la colina de Windows) puede constituirse como un medio empoderador y transformador- se trata de identificar esos procesos y adaptarlos de manera más o menos literal y evidente en forma de espacio educativo.

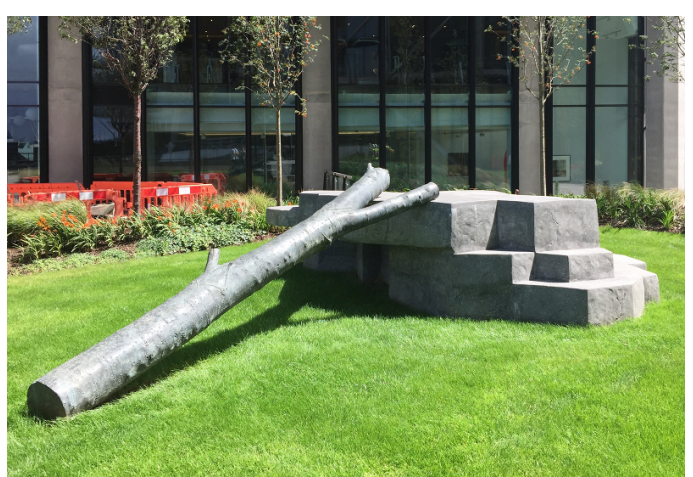


Figura 3. Terra Ludi, ${ }^{7}$ Simon \& Tom Bloor. Obra permanente, Nine Elms, London, 2015.

Este escenario de participación directa y descubrimiento -como diría Brunerfomenta el aprendizaje significativo, es decir, que son la propia experiencia y el propio discernimiento los que generan el conocimiento "real", resultante de un diálogo establecido entre el espacio y los componentes de este y uno mismo, de tal modo que el espacio en sí se constituye como una nueva realidad d'après cada uno. Así, existirán tantos conocimientos como diálogos se entablen.

Se asocia de esta forma el aprendizaje por descubrimiento con la distensión, la diversión y el juego, un juego entendido más como participación que como desahogo. En consecuencia, los espacios artificiales dedicados en exclusiva al juego, en general, deberán respetar estos principios, máxime cuando es a través del juego cuando nos suponemos en nuestro ejercicio libre. Sería muy confuso ejercer aquello que creemos como inherentemente propio bajo unas normas compresoras. Esto es, una pelota, como tal, como herramienta, presenta infinitas posibilidades de uso, sin embargo, un campo de fútbol, por ejemplo, con sus líneas y sus reglas adheridas, no representa para el jugador ningún estímulo significativo sino el desarrollo y perfeccionamiento de una destreza o habilidad.

\footnotetext{
${ }^{7}$ Ludi, en latín: juegos, diversión, entretenimiento (pan y circo), pero también escuela.
}

De este modo, se relaciona de forma directa el ejercicio de la "libertad" con el redil y el espacio delimitado para tal fin, con la alteridad, con el afuera. $Y$ se hace inminente derribar los muros y barreras que dictaminen los tiempos y las acciones. Así, no debería distinguirse una actividad según el espacio que ocupa, pues coarta cualquier posibilidad fuera de ese patrón.

Aun así, conocedor de que existe diferencia entre el adentro y el afuera en cuestión de actividades, no puede suponer una diferencia para con las libertades y las maneras de empoderamiento. Si no es posible destruir los cercados, no podemos sino destruir su cerco. No significa esto terminar por olvidar la función del cercado y adoptarlo como propio, todo lo contrario, se trata de identificar el espacio y apropiárselo para que tenga lugar la metamorfosis.

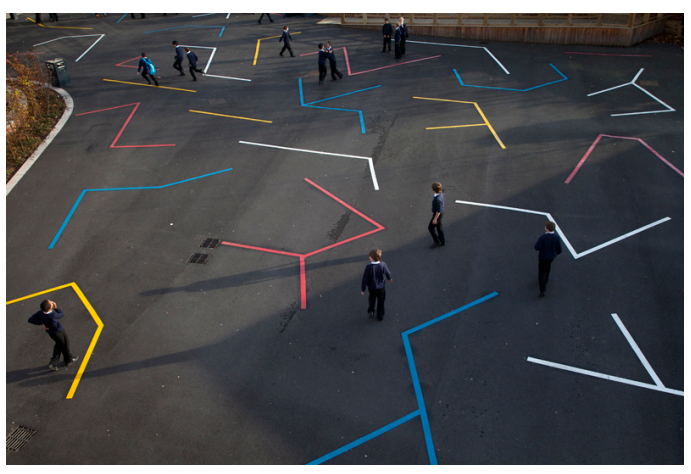

Figura 4. Formula for living, Simon \& Tom Bloor. Obra permanente, Cotham School, Bristol, 2011.

A riesgo de repetirme, el paisaje de aprendizaje libertario no solo no subyuga y propone un marco estimulante, sino 
La transformación estética del espacio educativo y su influencia en el proceso de enseñanzaaprendizaje

https://dx.doi.org/10.17561/rtc.n16.5

que supone un cambio de paradigma en cuanto a la construcción de las relaciones que se establecen en él. No es un lugar de paso, es un lugar habitado, de estancia, de interconexión, es la negación de un no-lugar.

Y así como al conocer la oscuridad se comprende la luz, al definir el no-lugar se concreta el lugar. En consecuencia, el no-lugar, término acuñado por Marc Augé (2000), sería aquel derivado por los procesos de globalización y sobremodernidad -otro término de Augéque alude al tiempo y al espacio de la superabundancia y el exceso, lo que plantea una nueva dimensión de la concepción de la historia, que se instaura en un eterno y cambiante presente. Es decir, los tiempos en recorrer el planeta se acortan ya sea a través de los veloces medios de transporte o por las vías de la tecnología, lo que hace inevitable que el espacio mismo se achique, así, la celeridad, la instantaneidad y la individualidad del momento presente olvidan a un pasado fugaz y no posibilitan la atención de un futuro.

Los no-lugares vendrían a ser los espacios del viajero -privilegiado exponencial del capitalismo- y la fast life: sin memoria del tiempo, impersonales, destinados a la transitoriedad.

\section{Son tanto las instalaciones} necesarias para la circulación acelerada de personas y bienes (vías rápidas, empalmes de rutas, aeropuertos) como los medios de transporte mismos o los grandes centros comerciales, o también los campos de tránsito prolongado donde se estacionan los refugiados del planeta (Augé, 2000).

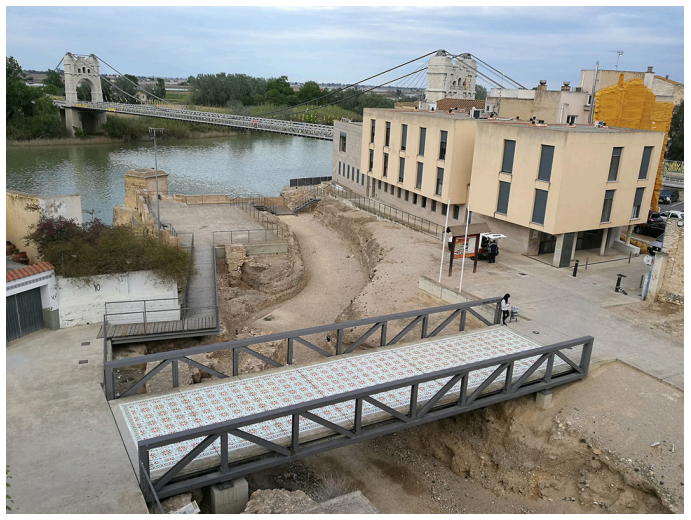

Figura 5. Pont, Javier de Riba. Amposta, Catalunya, $2018^{8}$

Los lugares, por el contrario, serían espacios de identidad, históricos y relacionales. Esto es, que el espacio no condiciona y predispone la movilidad y el comportamiento y no reduce el aspecto identitario humano al de un sujeto y objeto, sino que supone una puesta en valor de la condición social de la persona.

Sin embargo, ¿puede un espacio suponerse lugar y no-lugar al mismo tiempo? Es decir, ¿la condición de lugar o no-lugar pertenece al propio espacio o es subjetiva a la interpretación personal? Por ejemplo, si para mí el centro comercial no es un lugar alienante de

8 «Convertir un lugar de paso en un lugar de estancia. La situación migratoria es alarmante. Refugiados, desplazados y exiliados, personas a las que se les ha obligado a hacer vida en NoLugares» (De Riba, 2018). 
cruce, sino que significa un espacio de encuentro, de estancia y socialización, ¿dejaría el centro comercial de ser un nolugar para convertirse en un lugar? Es posible que, poco a poco, lleguemos a identificar como personales los lugares intrínsecamente impersonales, por lo que estaríamos asistiendo a una transformación de la intencionalidad e ideología del propio espacio.

El objetivo es, por tanto, no esperar la llegada de la utopía (que el Estado y sus espacios sean libertarios y no opresores), sino construirla a partir de la apropiación y subversión de lo dado. No asumir que la solución está en el afuera, en lo privado, sino aprovechar los subterfugios de lo público para luchar desde, por y para lo público. "¿existe un espacio público no estatal en el campo educativo?» -cuestiona Miriam Feldfeber (2003)- lo público trasciende a lo estatal al mismo tiempo que no es otra cosa que lo estatal. Esto es, se trata de asumir lo público como herramienta pública y no estatal.

Así, aunque el Estado decrete legalmente las normativas de diseño y constructivas para los edificios de uso docente (ORDEN de 24 de enero de 2003), no podrá dictaminar el tipo de relaciones que se gesten en torno a ellas. Del mismo modo que se desacraliza una iglesia para convertirse en biblioteca o en skate park o en hogar particular y se reduce el concepto de iglesia a la tipología espacial y no a unas determinadas y preasociadas maneras de conducta, movimiento en tiempo y espacio, vestimenta, interrelación, etc., el
Panóptico de Bentham, la escuela, será estatal como fisicidad, pero pública en su labor.

De esta forma, en nuestro hacer contestatario, debemos modificar los espacios institucionales estandarizantes de tránsito haciéndolos nuestros, okupándolos, habitándolos. Hasta que se tiren los muros y se construyan las escuelas libertarias empoderadoras que nos ocupan, habremos de instalar nuestras salas de estar en las celdas de la cárcel. jinsisto! No para hacer nuestra estancia más cómoda, sino para derrocar los intereses subyugantes de los barrotes.

Prescindiremos de su lenguaje y su metalenguaje. Ni la cárcel será cárcel, ni el aula, aula. Al nominarse de forma distinta y al albergar distinta actividad no podrán sino convertirse en otra cosa.

El aulario modular, repetitivo y fragmentario de la organización espaciotemporal da paso al espacio educativo polivalente que promueve la interrelación y que plantea que el aprendizaje puede suceder en diversos tiempos y espacios, a modo del learning landscape de Herman Hertzberger. ${ }^{9}$ Los pasillos, no-lugares insertos en macro no-lugares, a su vez, dejan de asistir a la tarea de conexión para contribuir al

\footnotetext{
${ }^{9}$ Arquitecto y pedagogo estructuralista holandés. Entiende la arquitectura como lo público, como lo colectivo, siendo las escuelas el máximo exponente de lo público. La estructura prevalece por encima de su función, es decir, la estructura plantea un marco y son las personas y el tiempo quienes completan el edificio.
} 
La transformación estética del espacio educativo y su influencia en el proceso de enseñanzaaprendizaje

https://dx.doi.org/10.17561/rtc.n16.5

concepto de hábitat, para así, no identificar aula ni pasillo, sino la comunidad escolar como tal.

Por tanto, un contexto educativo ideal debería permitir la versatilidad y la posibilidad de crear grupos con diferentes distancias proxémicas, con un equilibrio entre espacios privados y espacios públicos, entre espacios reflexivos y espacios de debate, en los que los alumnos puedan contar, también, con entornos más informales (Martire, 2017).

Se genera, entonces, el espacio que mantiene una relación dialógica para con la didáctica, que no discrimina fronteras intra y extraescolares, que relaciona no solo a las personas sino a los lenguajes y saberes, de la forma en que la estética (no la decoración) conecta y vincula aquellos elementos que se suponían aislados. «Debemos ser capaces de ver las relaciones antes que los términos relacionados» -decía Malaguzzi (Hoyuelos).

A propósito de Malaguzzi y su pedagogía, Reggio Emilia, supone un paradigma para con la asunción de una tipología espaciotemporal que al mismo tiempo actúa como metodología. Sus espacios, los atelieres, suponen una herramienta de experimentación en sí misma, donde a través de la expresión plástica se plasma esa idea de integración e interrelación de (los 100) lenguajes.

Se diluyen, por tanto, el espacio, el tiempo y la materia para devenir en la experiencia libertaria, crítica y empoderadora, y así como identificábamos el diálogo y el espacio educativo como aliados para tal vivencia, encontramos en las artes y la expresión plástica otro socio que avanza en igual dirección y con el mismo ímpetu.

Las artes -la música, la arquitectura, la danza, la fotografía, etcétera-, igual que las demás áreas de experiencia -la geografía, la salud, la ciencia, la tecnología, etcétera- son susceptibles de educación y constituyen, en cada caso, el área cultural específica que es el objetivo en la educación de las personas. Se puede hablar de la educación artística como ámbito general de educación. La educación artística es, antes que nada, educación y, por tanto, como educación, es, en cada persona, un proceso de maduración y aprendizaje que implica, desde las artes, el desarrollo de la inteligencia, la voluntad, la afectividad, la operatividad, la proyectividad y la creatividad, orientado al desarrollo de valores vinculados al carácter y al sentido inherentes al significado de la educación (Touriñán, 2016). 
Revista de Estudios en Sociedad, Artes y Gestión Cultural

Número 16

Julio 2019
ISSN: 2340-9096

https://dx.doi.org/10.17561/rtc.

Figura 6. All Schools should be Art Schools, Bob \& Roberta Smith. 2012.
http://revistaselectronicas.ujaen.es/index.php/RTC

www.terciocreciente.com

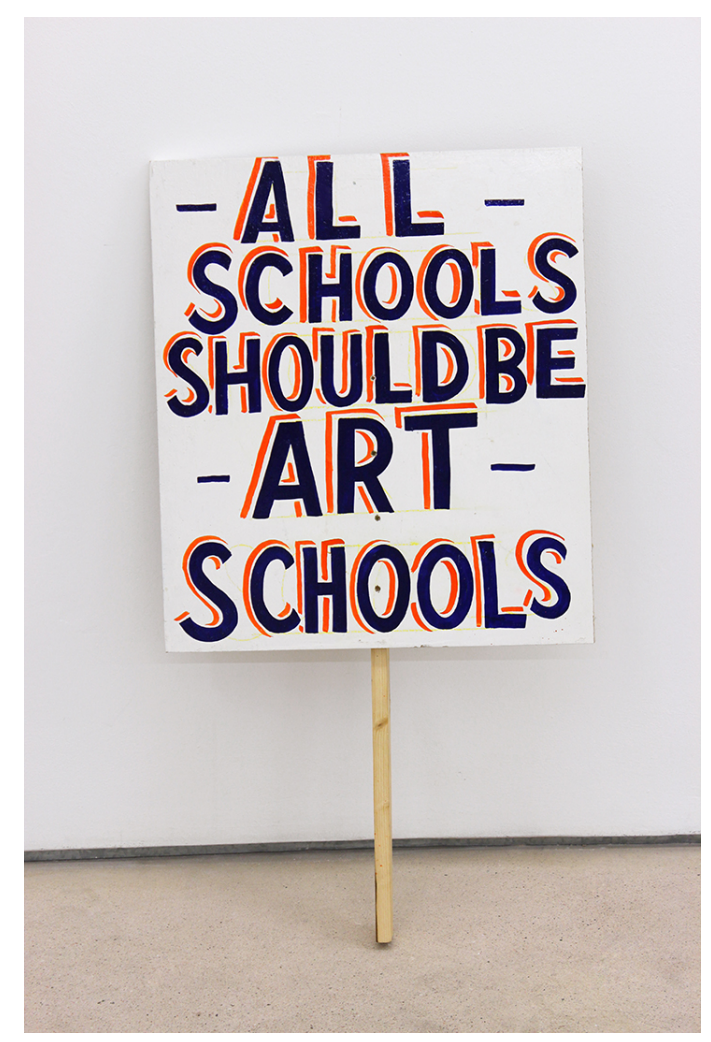


La transformación estética del espacio educativo y su influencia en el proceso de enseñanzaaprendizaje

https://dx.doi.org/10.17561/rtc.n16.5

\section{Referencias}

Augé, Marc (2000). Los no lugares. Espacios del anonimato. Una antropología de la Sobremodernidad. (M. Mizraji, Trad.) Barcelona: Gedisa.

Bertozzi, Sergio (2001). ¿En qué se parece la escuela a la prisión? Pontificia Universidad Católica Argentina Santa María del Buen Aire. Recuperado el 24 de abril de 2018, de https://www.fceia.unr.edu.ar/darquitectonico/darquitectonico/data/pdf/en\%20qu e\%20se\%20parece\%20la\%20escuela\%20a\%20la\%20prision.v2.pdf

Brown, Alex (2014). Los portadores de la antorcha, de Anna Hyatt Huntington. Fotografía. Recuperado el 19 de mayo de 2018, de https://elmadriddefranco.wordpress.com/2014/09/26/los-portadores-de-laantorcha-un-regalo-del-matrimonio-huntington-a-madrid-1955/

Castro, Ernesto (22 de marzo de 2018). La universidad en 1 minuto. Recuperado el 20 de mayo de 2018, de https://www.youtube.com/watch?v=crlJiyiQu8c

De Riba, Javier (mayo de 2018). Pont (Amposta, Catalunya). Recuperado el 04 de junio de 2018, de javierderiba.com: http://www.javierderiba.com/works/category/floors

Di Paolo, Javier (s.f.). La importancia del medio ambiente en el proceso de aprendizaje. Monografía Curso de Capacitación Docente en Neurociencias. Asociación Educar. Recuperado el 31 de mayo de 2018, de http://www.asociacioneducar.com/monografias-docenteneurociencias/monografia-neurociencias-javier.di.paolo.pdf

Dufour, Ivonne Alejandra (2016). La obsololescencia "programada" de la escuela pública: redes, contratos y costos de transacción. Tesis Doctoral, Universidad Autónoma de Barcelona. Recuperado el 18 de mayo de 2018, de https://www.tdx.cat/bitstream/handle/10803/400436/iaid1de1.pdf? sequence=1

Felderber, Miriam (2003). Los sentidos de lo público. Reflexiones desde el campo educativo ¿existe un espacio público no estatal? Buenos Aires: Novedades Educativas.

Flecha, Ramón, \& Tortajada, Iolanda (1999). Retos y salidas educativas en la entrada de siglo. En F. Imbernón, La educación en el siglo XXI. Los retos del futuro inmediato. Barcelona: GRAÓ.

Foucault, Michel (2012). Vigilar y castigar; Nacimiento de la prisión. Madrid: Biblioteca Nueva. 
Freire, Paulo (1971). Quelques idées insolites sur l'éducation. Commission internationale sur le developpement de l'éducation. Série B: Opinions. $N{ }^{\circ} 36$. Unesco.

Freire, Paulo (1975). Pedagogía del oprimido. (J. Mellado, Trad.) Madrid: Siglo XXI.

Galicia, Nuria (2004). Las relaciones de poder en el aula: género y pedagogía. I Congreso de Enseñanza de la Filosofía en Castilla y León. Facultad de Filosofía. Universidad de Valladolid. Recuperado el 17 de mayo de 2018, de http:// www.fyl.uva.es/ wfilosof/textosense\%F1anza/foucault.doc

Gramsci, Antonio (1973). La alternativa pedagógica. Barcelona: Nova Terra.

Hasél, Pablo (21 de septiembre de 2011). Pablo Hasél,,, La educación es la base. Recuperado el 18 de mayo de 2018, de https://www.youtube.com/watch?v=Slql11Rdels

Hoyuelos, Alfredo (s.f.). Reggio Emilia y la pedagogía de Loris Malaguzzi. (N. Educativas, Entrevistador)

Ibisate, Francisco Javier (1998). Neoliberalismo y globalización. Revista ECA, 600. Recuperado el 19 de mayo de 2018, de http://www.uca.edu.sv/publica/ued/ecaproceso/ecas_anter/eca/600art1.html

Jones, Owen (08 de mayo de 2017). Otra Vuelta de Tuerka - Pablo Iglesias con Owen Jones (programa completo). La Tuerka. (P. Iglesias, Entrevistador) Recuperado el 19 de mayo de 2018, de https://www.youtube.com/watch?v=SgytMGfGF6A

Larrosa, Jorge (2009). Experiencia y alteridad en educación. En C. Skliar, \& J. Larrosa, Experiencia y alteridad en educación (págs. 13-44). Rosario, Argentina: Homo Sapiens Ediciones.

Ley Orgánica 8/2013. (s.f.). para la Mejora de la Calidad Educativa (LOMCE), Boletín Oficial del Estado (BOE). 10 de diciembre de 2013. (295).

López Cuenca, Rogelio (25 de Marzo de 2015). El elefante blanco y la marabunta. Recuperado el 25 de Marzo de 2018, de La Opinión de Málaga: http://www.laopiniondemalaga.es/cultura-espectaculos/2015/03/24/elefanteblanco-marabunta-i/753433.html

Martire, Antonio (08 de febrero de 2017). Antonio Martire: "El contexto físico y tecnológico debe responder a un diseño didáctico compartido". (A. Montero, Entrevistador) Recuperado el 04 de junio de 2018, de http://www.aikaeducacion.com/entrevistas/antonio-martire-contexto-fisicotecnologico-responder-diseno-didactico-compartido/

Mészarós, István (2008). La educación más allá del capital. Buenos Aires, Argentina: Siglo XXI; CLASCO. 
La transformación estética del espacio educativo y su influencia en el proceso de enseñanzaaprendizaje

https://dx.doi.org/10.17561/rtc.n16.5

Montero, Anna (05 de febrero de 2017). El diseño se cuela en las aulas. Recuperado el 02 de junio de 2018, de Aika. Diario de Innovación y Tecnología en Educación: http://www.aikaeducacion.com/tendencias/diseno-se-cuela-lasaulas/

Ovejero, Anastasio, \& Pastor, Juan (2001). La dialéctica saber/poder en Michel Foucault: Un instrumento de reflexión crítica sobre la escuela. Aula Abierta(77), 99-107. Recuperado el 17 de mayo de 2018, de https://dialnet.unirioja.es/descarga/articulo/45498.pdf

Pallier, María (Dirección). (2018). Metrópolis - DAK'ART 1: La hora Roja (I) [Película]. Recuperado el 29 de mayo de 2018, de http://www.rtve.es/alacarta/videos/metropolis/metropolis-dakart-1-horaroja/4611552/

Pasquali, Antonio (1967). Comunicación y cultura de masas. Caracas, Venezuela: Monte Ávila Editores.

Rattero, Carina (2009). La pedagogía por inventar. En C. Skliar, \& J. Larrosa, Experiencia y alteridad en educación (pág. 161). Rosario, Argentina: Homo Sapiens Ediciones.

Real Academia Española. (diciembre de 2017). vital. Versión electrónica de la 23. ${ }^{a}$ edición del "Diccionario de la lengua española". Recuperado el 17 de mayo de 2018, de http://dle.rae.es/?id=bwCD3eL

Rousseau, Jean-Jacques (2011). Emilio o De la educación. Alianza Editorial.

School of the Built Environment. (noviembre de 2012). Improved Learning Through Classroom Design. University of Salford, Manchester. Recuperado el 31 de mayo de 2018, de https://www.salford.ac.uk/business/consultancy/casestudies-nightingale-schools

Spring, Joel (1987). Introducción a la educación radical. Madrid: Akal.

Tedesco, Juan Carlos (1995). El nuevo pacto educativo. Educación, competitivad y ciudadanía en la sociedad moderna. Madrid: Anaya.

Tonucci, Francesco (12 de Septiembre de 2013). Tonucci: "El alimento de la escuela debería ser la experiencia de los niños". (Tiching, Entrevistador) Recuperado el 29 de Marzo de 2018, de http://blog.tiching.com/francesco-tonucci-el-alimentode-la-escuela-deberia-ser-la-experiencia-de-los-ninos/

Touriñán, José Manuel (2016). Educación artística: Sustantivamente "educación" y adjetivamente "artística". Educación XXI, 19(2), 45-76. doi:10.5944/educXX1.14466

Trilla, Jaume, \& Puig, Josep M. (junio de 2003). El aula como espacio educativo. Cuadernos de Pedagogía(325), 52-55. 